\title{
Acreditación de Escuelas de Medicina: Trabajando para la Calidad y la Confiabilidad Pública
}

\author{
Prof. Dr. Eduardo Rosselot J aramillo. \\ Presidente Comisión Central Autoevaluación, \\ Escuela de Medicina, Universidad de Chile ${ }^{1}$
}

El procedimiento de acreditación de la Educación Superior en Chile, ha alcanzado un punto significativo al completarse la primera versión para tres de las seis Escuelas de Medicina agrupadas en la Asociación de Facultades de Medicina de Chile, ASOFAMECH, en virtud del acuerdo suscrito en 1998 por el Consejo Superior de Educación con ese $\operatorname{organismo}^{2-3}$. Las tres restantes, están en proceso de cubrir igual trámite antes que termine el año 2001.

Frente a la consolidación de un modelo mundial, de cada vez más eficiente y reglada aplicación para regular los programas y las instituciones de educación superior, que estos hechos traducen, y a lo que esto significa dentro de las políticas de mejoramiento y sostén de la calidad educacional en el país, la difusión de los resultados de esta acreditación es de gran utilidad para afinar estos procedimientos innovadores y establecer las bases de un sistema confiable y exitoso. Entre otros aspectos, es importante conocer las circunstancias en que se ha realizado el proceso y los inconvenientes o virtudes manifestadas durante su desarrollo.

Hasta ahora, las Escuelas de Medicina de la Universidad de Valparaíso y de la Universidad La Frontera de Temuco, han recibido acreditación por dos años, período dentro del que se supone deberán cumplir tareas específicas para satisfacer todos los requisitos mínimos de acreditación contemplados en el acuerdo referido. La Escuela de Medicina de la Universidad de Chile, ha sido acreditada por siete años, que se considera el período máximo por el cual se otorga dicho reconocimiento - con relación a la duración mínima teórica de la carrera -, sin perjuicio de que deba, también, al cabo de ese lapso, responder de ciertas observaciones destinadas a corregir debilidades, superables en el plazo previsto, para cautelar la calidad de sus procesos educativos.

Desde la perspectiva de esta última universidad, en cuya autoevaluación nos correspondió participar directamente, parece pertinente revisar las dificultades encontradas en el desarrollo del proceso y los beneficios inmediatos advertidos a raíz de la acreditación.

Dificultades del proceso de autoevaluación

En la experiencia con procesos de evaluación que podrían considerarse precedentes a los realizados en nuestras Escuelas de Medicina, se describen situaciones que dificultan

\footnotetext{
1. Integraron dicha Comisión, además, los Profesores Alejandro Goic, Carmen Velasco, Alberto Edwards, Rafael Blanco, Julio Palavicini, Julia González, Eugenia Jedlicki, Carmen Larrañaga y Cristel Hanne.

2 Integran la ASOFAMECH, las Facultades de Medicina de las Universidades de Chile, Pontificia Universidad Católica de Santiago, de Concepción, de Valparaíso, La Frontera de Temuco y Austral de Valdivia.

${ }^{3}$ Rosselot E.- Entre la renovación curricular y la acreditación. Calidad en la Educación. 1999; julio: 65 - 69
} 
significativamente su desarrollo o terminan desvirtuando sus propósitos e impidiendo la obtención de los beneficios esperados de la acreditación.

Elemento central de análisis en la autoevaluación, es la misión explícita de la institución, respecto a la cual se ponderan los recursos disponibles o asignados y los logros. Sea que ella no haya sido formulada o sea desconocida tanto por el cuerpo académico como por los estudiantes, tal situación establecerá una dificultad mayor para la consecución de los objetivos del programa y, asímismo, para la evaluación de su efectividad.

De igual manera puede determinar un lastre, eventualmente insuperable, la inexistencia de una cultura de evaluación institucional, en especial, y también, de los programas y del desempeño académico. Los controles a los alumnos, como forma de calificación para decidir sobre rendimiento académico y promoción, son, por lo general, las únicas evaluaciones aceptadas por el sistema dentro de la estructura del proceso docente, declinando y despreciando este tipo de datos de análisis que pueden aportar interesantes y útiles elementos de información sobre calidad de los programas, aptitudes de los docentes, o constituir apoyo eficaz para el mismo proceso de aprendizaje. Se suma a ello que los objetivos de la autoevaluación no sean compartidos en forma apropiada por los involucrados en el proceso y la consiguiente o simultánea resistencia a los cambios que aparece, habitualmente, cuando se introducen nuevas acciones a cualquier sistema.

Otra dificultad obvia es la producida cuando está ausente el requerido liderazgo para convocar a la comunidad a un proceso de esta magnitud y, ni las autoridades ni el cuerpo docente o los alumnos, se sienten motivados a llevarlo a cabo por carecer de estímulos adecuados o no apreciar los objetivos inmediatos o tardíos del proceso.

La Escuela de Medicina de la Universidad de Chile no ha tenido mayores dificultades en estos aspectos, aunque una misión no perfectamente difundida, una débil o incipiente cultura evaluativa e insuficiente interés en la autoevaluación y cierta resistencia a los cambios, remanente de la reacción a la renovación curricular en curso, puede haber provocado, en ciertos niveles, un ánimo de prescindencia.

Pero, sin duda, la complejidad estructural de la Escuela, especialmente su extensión física repartida en cinco campus, la multiplicidad de unidades a cargo de diversos programas, la heterogeneidad de compromisos académicos y la existencia de numerosas actividades agregadas a la docencia, representa un factor de considerable implicancia. Al igual que el hecho de que la Escuela haya estado desarrollando una renovación curricular efectiva y profunda, con dos modelos en curso a medida que las innovaciones abarcan niveles más adelantados, ha sido un escollo relativo para la ejecución de los procesos y la interpretación de la información. Finalmente, no puede soslayarse que dificultades de socialización y comunicación, también vinculadas a las anteriores circunstancias, sino a insuficiencia de recursos o diseños apropiados, entorpecieron, más de una vez, la ejecución más expedita, oportuna y efectiva de trámites requeridos para un procedimiento más acabado.

Beneficios advertidos a raíz de la autoevaluación.

Completado el proceso de autoevaluación, e independiente del dictamen final, pero sí reforzado por el informe de pares externos y las sugerencias planteadas por ellos, ha sido posible advertir ya algunos efectos que determinarán, a la larga, cambios más trascendentes para el desarrollo de la institución y sus programas. 
Desde luego, se percibe el asentamiento de una conveniente cultura evaluativa. Hay clara conciencia de que debe lograrse mayor avance y ampliación de estos procesos, de los cuales no puede sino surgir una resuelta voluntad y capacidad de cambio, innovaciones sustantivas en los programas y en las metodologías docentes, aprovisionamiento de nuevos recursos y re encantamiento, por el desarrollo de iniciativas de fortalecimiento y creatividad en diversos ámbitos académicos. Rápidamente, las restantes Escuelas de la Facultad se han comprometido a iniciar sus propios sistemas de autoevaluación, a revisar sus currícula, a buscar inexplorados derroteros para insistir en alcanzar metas de mayor calidad. No cabe duda que se ha despertado un nuevo entusiasmo para enfrentar los planes estratégicos de la Facultad, así como mantenerse alerta a verificar el cumplimiento de las reformas en el currículum, las recomendaciones de la acreditación, la rigurosidad de los compromisos académicos vigentes o por emprender.

Ha sido reconfortante la oportunidad de tomar conciencia de virtudes y potencialidades, que existiendo en muchas de las unidades evaluadas, ha sido dable reconocerlas a raíz de la relevancia que les otorgó el proceso de autoevaluación y la confirmación del informe externo.

Hay una decisión institucional, que se hace explícita y operativa, de mantener un programa permanente de mejoría y aseguramiento de la calidad educacional, y se comienzan a tomar medidas para integrar tales propósitos, así como sus contenidos, al curriculum y hacerlos, cada vez, más exigibles en la organización, el desempeño y los productos de la actividad académica.

De importancia procesal, se verifica que el sistema de autoevaluación constituye una herramienta fundamental para un análisis, a la par que amplio y comprensivo, de gran utilidad para determinar un conocimiento actualizado de la institución, sus fortalezas y debilidades, su capacidad y su potencial, al lado de sus limitaciones y su aptitud para alcanzar superación. Aunque sea efectuado por miembros involucrados en el proceso a evaluar, por su lógica pertenencia institucional, es dable llevar a cabo sus diferentes etapas con suficiente imparcialidad, tal vez con excesiva autocrítica en vez de formal complacencia, permitiendo confirmar sus virtudes y objetividad al contrastar sus conclusiones con las de los pares externos y la ulterior acreditación.

\section{Coda}

La experiencia que agreguen las Universidades de Concepción, Austral y Pontificia Universidad Católica de Santiago, será de una trascendencia indudable para producir, avalar y dar consistencia al modelo de acreditación resuelto por el Ministerio de Educación y sometido a prueba en esta etapa. Habrá que avanzar en otras dimensiones para disipar aprensiones sobre la trascendencia de estos procesos; las consecuencias tanto de la acreditación como de la no acreditación eventual; el grado de divulgación que habrá que otorgar a las conclusiones; la repercusión fuera de las fronteras del país y en la transferencia de las capacidades y de su ejercicio; la configuración y los constituyentes de un organismo acreditador amplio y universalmente confiable o, como alternativa, de un conjunto de agencias acreditadoras. En fin, sobre la obligatoriedad y las formas de legalización o generalización del sistema.

Pero, comenzando a andar, como se ha hecho, y apreciadas sus cualidades aunque haya que superar dificultades y afianzar sus beneficios antes de obtener una 
aceptación global, el camino está diseñado para lograr paulatino perfeccionamiento y adhesión a un proceso donde la búsqueda de calidad es la meta inobjetable y la adhesión a ese propósito una obligación ineludible. 